\title{
Problems encountered in recruiting patients to an ophthalmic drug trial
}

\author{
A M QUICK, P T KHAW, AND A R ELKINGTON \\ From the University of Southampton, Southampton Eye Hospital
}

SUMMARY Two clinical trials to assess the efficacy of two topical beta-blocker preparations involved the recruitment of 60 and 40 patients respectively. The greatest obstacle encountered in carrying out the trials was recruiting patients. This difficulty is reported in detail and comparisons are made with the experience of others who have met similar problems.

All who have carried out clinical research will be aware that the recruitment of patients often poses major difficulties. It is only too easy to overestimate the number of patients who will both agree to take part in any study and will satisfy the inclusion criteria. However, in spite of this difficulty being commonplace, there is little information in the ophthalmic literature on the likely scale of the problem. We therefore took the opportunity of documenting the erosion of the number of patients originally identified as possibly being suitable for inclusion in two studies of the efficacy of two beta-blocker drugs. Our aim in quantifying the problems encountered is to give guidance to others undertaking similar studies.

The trials involved recruiting a statistically determined number of patients to allow comparison of the effects of the two preparations in the treatment of patients with either chronic open-angle glaucoma or ocular hypertension. The first study was a singlemasked randomised crossover trial. The 60 patients were required to attend hospital on five occasions at three weekly intervals over a 12 -week period. On three of these visits patients were required to arrive at the hospital at 9 am and stay until $5 \mathrm{pm}$. On the two remaining visits patients needed to spend no longer than half an hour in the hospital.

The second study was a randomised evaluation of both preparations in which the patients received only one of the drugs over a period of 12 months. The 40 patients were required to attend hospital for between 30 minutes and 2 hours on six occasions.

\section{Materials and methods}

The names of patients for possible inclusion in the Correspondence to Mrs A M Quick, SRN, OND, Southampton Eye Hospital, Wilton Avenue, Southampton SO9 4XW. studies were derived from three sources; the outpatients' diagnostic index, members of the medical staff, and the medical secretaries. Patients were

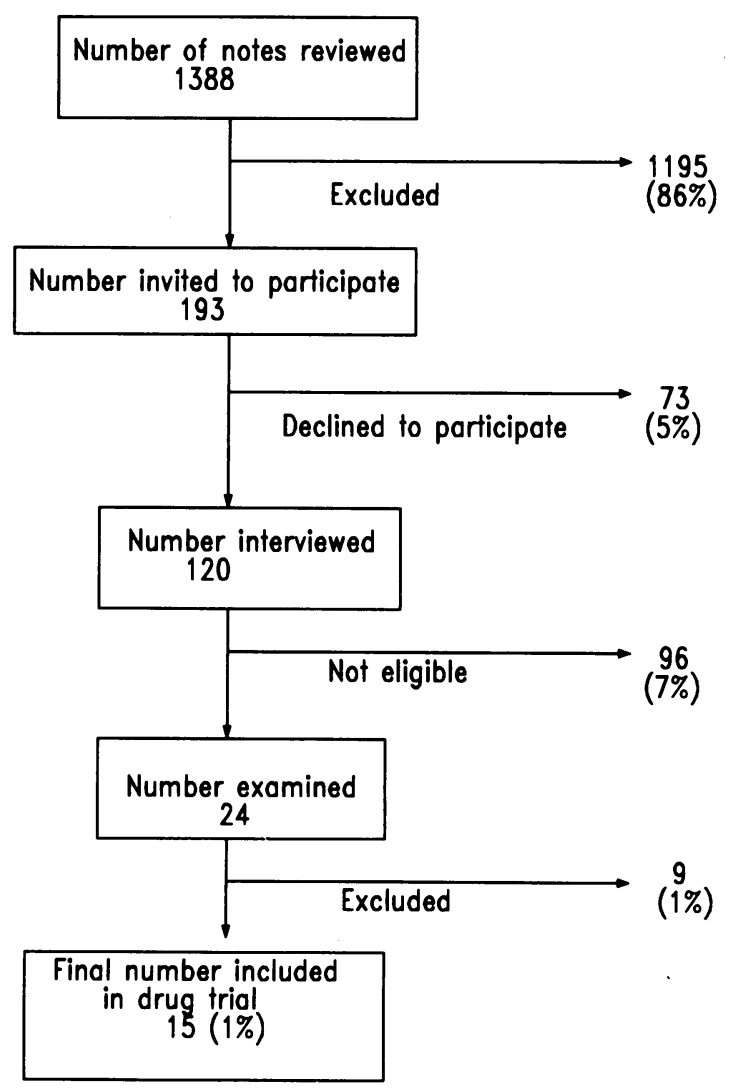

Fig. 1 Summary of steps in identification of patients. 
Table 1 Definitions of chronic open-angle glaucoma and ocular hypertension

Definition of chronic open-angle glaucoma:

(i) Intraocular pressure $>21 \mathrm{mmHg}$

(ii) Glaucomatous cupping of the optic disc

(iii) A glaucomatous visual field defect

(iv) An open angle on gonioscopy

Definition of ocular hypertension:

(i) Intraocular pressure $>21 \mathrm{mmHg}$

(ii) Normal optic disc

(iii) Normal visual field

(iv) An open angle on gonioscopy

considered if they were diagnosed as having either chronic open-angle glaucoma or ocular hypertension or if they were suspected of having glaucoma for any reason other than a raised intraocular pressure.

The recruitment of patients was carried out in the following four stages:

Stage $A$. The patients' hospital records were retrieved and the relevant notes were scrutinised. The records of patients not fulfilling the inclusion criteria were rejected.

Stage B. A letter was then sent to those patients

\section{Table 2 Exclusion criteria}

(i) Patients younger than 18 and older than 80 years of age

(ii) Ocular diseases such as infection, inflammation, or corneal ulceration occurring within one month prior to the study

(iii) Entry of foreign matter into the cornea within one month prior to the study

(iv) Patients who wear contact lenses or who stopped wearing them within one month prior to the study

(v) Intraocular operation or ocular injury within six months prior to the study

(vi) All aphakic patients

(vii) Patients with either secondary glaucoma or angle closure glaucoma

(viii) History or evidence of a serious retinal condition

(ix) History or evidence of bronchial asthma, chronic bronchitis, or other respiratory diseases

(x) Cardiac insufficiency, myocardial infarction, cerebrovascular insufficiency, or aortic stenosis

(xi) Sinoatrial or atrioventricular block as shown on an electrocardiogram

(xii) Diabetes mellitus

(xiii) Bradycardia (less than 55 beats per minute)

(xiv) Melanoma or other malignancy that may give rise to ocular metastases

(xv) Pregnant women or nursing mothers

(xvi) History of intolerance to timolol

(xvii) Patients who were judged by the attending investigator to be unsuitable for the studies

(xviii) Prohibited drugs for concurrent medication were: other antiglaucoma agents apart from timolol; parasympathetic nerve stimulants; sympathetic nerve stimulants; carbonic anhydrase inhibitors; beta-adrenergic blocking agents: hypotensive agents (not including diuretics); tricyclic antidepressants; beta-adrenergic stimulants; oral and topical corticosteroids; monoamine oxidase inhibitors
Table 3 Reasons for rejecting the case records of 1195 patients (stage A)

\begin{tabular}{lcc}
\hline & \multicolumn{2}{c}{ Number of case records } \\
\cline { 2 - 3 } & $\begin{array}{l}\text { Number } \\
\text { excluded }\end{array}$ & $\begin{array}{l}\text { Number } \\
\text { remaining }\end{array}$ \\
\hline Original number of case records & & 1388 \\
Glaucoma suspects & 449 & 939 \\
Multiple treatment & 252 & 687 \\
Notes missing & 176 & 511 \\
Serious eye disease & 53 & 458 \\
Narrow angles & 45 & 413 \\
Trabeculectomy & 35 & 378 \\
Lived too far away & 27 & 351 \\
On prohibited drugs & 26 & 325 \\
Respiratory problems & 23 & 302 \\
Diabetes mellitus & 19 & 283 \\
Secondary glaucoma & 19 & 264 \\
Cerebrovascular disease & 16 & 248 \\
Aphakia & 15 & 233 \\
Cardiac disease & 12 & 221 \\
Died recently & 10 & 211 \\
Low-tension glaucoma & 8 & 203 \\
Malignancies & 7 & 196 \\
Thyroid disease & 3 & 193 \\
\hline
\end{tabular}

Number of case records rejected $=1195(1388-193) .193$ patients were then invited for interview, 120 patients agreed to be interviewed, 96 patients were found unsuitable (see Table 4).

who were thought suitable for inclusion in the studies. This set out the aims of the projects, and the patients were asked to return a slip indicating whether or not they wished to be contacted by telephone to be given further particulars.

Stage $C$. The returned slips were collected and the contents of the replies noted. The patients who indicated an interest in participating in the studies were invited to the hospital and interviewed.

Stage $D$. The patients were subsequently examined. After a full medical and surgical history had been taken, perimetry and electrocardiography were performed and the pulse and blood pressure were recorded.

This routine is summarised in the flow chart (Fig. 1). The definitions of chronic open-angle glaucoma and ocular hypertension as applied in these studies are given in Table 1. The exclusion criteria are set out in Table 2.

\section{Results}

The reasons for rejecting the case records of 1195 patients from an original 1388 (stage A) are shown in Table 3. Of the remaining 193 patients who were invited to take part in the studies (stage B) 120 agreed to be interviewed. At interview (stage C) 96 patients were excluded from the trials for the reasons shown in Table 4. Table 5 shows the reasons for a further 
Table 4 Reasons for 96 patients being excluded after being interviewed (stage C)

\begin{tabular}{|c|c|c|}
\hline & \multicolumn{2}{|c|}{ Number of patients } \\
\hline & $\begin{array}{l}\text { Number } \\
\text { excluded }\end{array}$ & $\begin{array}{l}\text { Number } \\
\text { remaining }\end{array}$ \\
\hline Number of patients & & 96 \\
\hline Prohibited drugs & 25 & 71 \\
\hline Extensive field loss & 14 & 57 \\
\hline Cerebrovascular disease & 12 & 45 \\
\hline Respiratory disease & 11 & 34 \\
\hline Diabetes mellitus & 7 & 27 \\
\hline Unable to take time off work & 5 & 22 \\
\hline Cardiac disease & 5 & 17 \\
\hline Not actually instilling timolol & 4 & 13 \\
\hline Unwilling to take part in study & 3 & 10 \\
\hline On multiple treatment & 3 & 7 \\
\hline Trabeculectomy & 3 & 4 \\
\hline Bradycardia & 2 & 2 \\
\hline Unreliable perimetry & 2 & 0 \\
\hline
\end{tabular}

nine patients being excluded after they were examined (stage D). Hence, only 15 patients were recruited from an original 1388 case records - a ratio of 1:92-5.

\section{Discussion}

The problems we encountered will be recognised by any one involved in clinical research. As Hamilton put it, 'In any investigation involving human subjects the most difficult part is getting hold of them.' It was a great boon having an outpatient diagnostic index to which to refer in the first instance. ${ }^{2}$

In his review of the practical problems encountered in carrying out collaborative clinical trials Ederer $^{3}$ refers to the so called Muench's third law, ${ }^{4}$ which states that the number of patients promised for a clinical study must be divided by a factor of at least 10. Several studies from other disciplines have documented the progressive loss of patients who were initially identified as likely to be suitable for inclusion in the trials. In the National Diet Heart Study ${ }^{5}$ only

Table 5 Reasons for nine patients being excluded after being examined (Stage D)

Cardiac abnormalities diagnosed on electrocardiogram

Bradycardia

Changed to multiple treatment

Using hydrocortisone ointment for psoriasis

Over 80 years of age

Pathology identified on chest $x$-ray

Patient thought unlikely to complete study

Total
899 entrants to the trial were found after almost 20000 people had been screened - a ratio of 1:22.

Other workers have had results even more akin to our own. In one component of the Hypertensive Detection and Follow-up Study 5314 entrants were discowered among 436679 contacts - a ratio of 1:82. In the Coronary Primary Prevention Trial 3810 individuals took part out of the 436679 people originally considered $(1: 115)$. Similarly, in the Veterans Administration Mild Hypertensive Study ${ }^{*}$ 1012 participants were recruited from the 120000 who were first approached (1:119). Finally, the recruitment to the pilot study of the Systolic Hypertension in the Elderly programme $\mathrm{e}^{4}$ was no more than 551 individuals from approximately 75000 people originally contacted - a ratio of 1:136.

In view of our experience, and that of many others, ${ }^{10}$ we suggest that the prudent research worker should divide by 100 the number of individuals he initially thinks may be eligible for a trial rather than by 10 as previously suggested. In this way later embarrassment will be more often avoided and fewer promises will be broken.

We thank Mr M J Absolon, Mr I H Chisholm, Mr J I McGill, and Mr C B Walker for permission to study patients under their care. We are also greatly indebted to the junior members of the medical staff, the medical secretaries, and the staff in the Medical Records Department for their tremendous help in assisting us with this project. Finally we thank the patients who took part in the study.

\section{References}

1 Hamilton M. Computer programmes for the medical man: a solution. Br Med J 1965; ii: 1048-50.

2 Elkington AR, Davies JC. Setting up an out-patient diagnostic index. Proc Soc Med 1980; 73: 646-8.

3 Ederer F. Practical problems in collaborative clinical trials. Am J Epidemiol 1975: 102: 111-8.

4 Bearman JE, Loewenson RB, Gullen WH. Muench's postulates, laws and corollaries. Biometrics Note No. 4. Bethesda National Eye Institute, NIH: 1974.

5 Study personnel. Recruitment of participants. National Diet Heart Study: Final report, chapter 2. Monograph No18. Circulation 1968: 37 (suppl I): 1-40.

6 Members of the Writing Committee: Astostolides A, et al. Hypertension detection and follow-up. Program co-operative group. Patient participation in a hypertension control program. JAMA 1978; 239: 1507-14.

7 Writing group: Agras WS, et al. Lipid research clinics program: participant recruitment to the coronary primary prevention trial. J Chron Dis 1983; 36: 451-65.

8 Perry HM Jnr. Treatment of mild hypertension: preliminary results of a two-year feasibility trial. Circ Res 1977; 40 (suppl 1): $1-180$.

9 Vogt TM, Ireland CC, Black D, Camel G, Hughes G. Recruitment of elderly volunteers for a multicenter clinical trial: the SHEP study. Controlled Clin Trials 1986: 7: 118-33.

10 Recruitment to clinical trials: the lipid research clinics coronary primary prevention trial experience. America Heart Association Monograph No. 93. Circulation 1982; 66 (suppl 4): 2-78.

Accepted for publication 19. September 1988. 